\title{
Sutureless anastomoses of rabbit carotid arteries with BioGlue
}

\author{
Wolfgang Schiller, MD, ${ }^{a}$ Heike Rudorf, DVM, ${ }^{\mathrm{b}}$ Christoph B. Welzel, MD, ${ }^{\text {a }}$ Martin J. Kiderlen, MD, ${ }^{\text {a }}$ Chris Probst, MD, ${ }^{a}$
} Oliver Dewald, MD, and Armin Welz, MD ${ }^{a}$

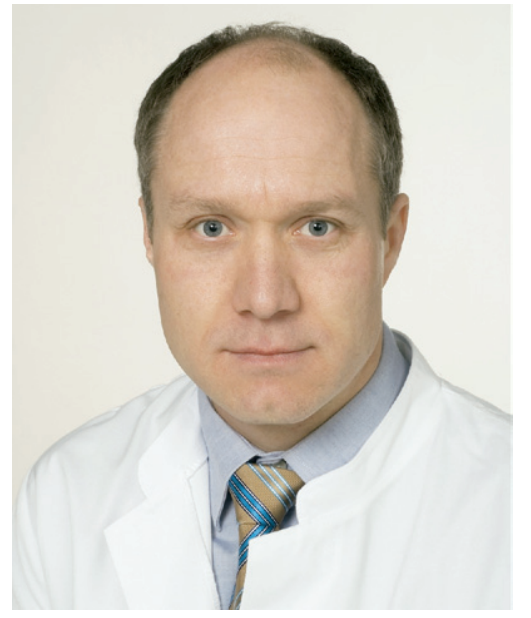

Dr Schiller
Objective: Sutureless anastomoses for coronary artery surgery are being investigated for a minimally invasive setup because they are easy to perform and less timeconsuming than are sutured anastomoses. The short-term effects of the biocompatible adhesive BioGlue on vascular tissue have been described as potentially unfavorable. The present study investigates the medium-term macroscopic and histologic effects associated with the use of BioGlue on rabbit carotid arteries.

Methods: Thirty-four carotid arteries of 17 New Zealand White rabbits were available. Nine carotid arteries were left unmanipulated and free of glue, 9 carotid arteries had BioGlue applied as a control, and 16 carotid arteries were transected and reanastomosed with the aid of BioGlue and an endovascular balloon. Of the 16 transected arteries, 4 had to be excluded from further evaluation. Angiographic scanning was performed 60 days postsurgery, after which the animals were euthanized and tissue samples were obtained for macroscopic and histologic examination.

Results: The application of BioGlue resulted in a marked invasion of inflammatory cells. The glue partially degraded and was replaced with connective tissue. Obvious calcification of the arterial wall and the capsule that had formed around the glue was present. Stenoses, thrombi, and pseudoaneurysms were predominantly noted in the glued anastomosis group.

Conclusion: The results of this study raise concerns about the safety of BioGlue in coronary artery surgery. In light of our results, the use of BioGlue in large-vessel vascular surgery should be considered with great care for each individual patient.

$\mathrm{S}$ uturing coronary anastomoses is a time-consuming procedure and is difficult to perform in the limited space available during minimally invasive surgery. Tissue adhesives that do not require lengthy suturing procedures or a large amount of space seem to be the way forward. ${ }^{1}$

Several types of adhesives have been successfully used as tissue strengtheners and hemostatic agents. The adhesive BioGlue (CryoLife International Inc, Kennesaw, Ga) does not contain the toxic agent formaldehyde and is licensed for the open surgical repair of large vessels. Gundry and colleagues ${ }^{1}$ reported good results with the in vivo use of BioGlue for coronary anastomoses in 3 goats, and van Nooten and colleagues $^{2}$ described the same procedure as moderately successful in 8 dogs. Wippermann and coworkers ${ }^{3}$ found severe inflammatory reactions associated with the use of BioGlue in porcine coronary artery surgery when they compared 3 different types of adhesives. The short-term study of our group ${ }^{4}$ identified a marked inflammatory response as early as 2 days after application of the glue to rabbit carotid arteries; stenoses, thrombi, and pseudoaneurysms were also noted. The present study investigated the morphologic and histologic changes of the rabbit carotid artery 60 days after a completely sutureless anastomosis with BioGlue. 
TABLE 1. Histologic findings in $\mathbf{3 0}$ of $\mathbf{3 4}$ arteries

\begin{tabular}{|c|c|c|c|c|c|c|}
\hline Glued anastomosis & Animal No. & Side & Macrophages & Granulocytes & Foam cells & Giant cells \\
\hline & 1 & $\mathrm{R}$ & 3 & 0 & 3 & 2 \\
\hline & 2 & $\mathrm{R}$ & 2 & 0 & 3 & 2 \\
\hline & 3 & $\mathrm{R}$ & 2 & 1 & 2 & 1 \\
\hline & 4 & $\mathrm{R}$ & 3 & 1 & 2 & 1 \\
\hline & 5 & $\mathrm{R}$ & 2 & 1 & 2 & 2 \\
\hline & 6 & $\mathrm{R}$ & 2 & 1 & 2 & 1 \\
\hline & 7 & $\mathrm{R}$ & 2 & 1 & 2 & 1 \\
\hline & 8 & $\mathrm{R}$ & 2 & 1 & 3 & 2 \\
\hline & 9 & $\mathrm{R}$ & 3 & 1 & 3 & 2 \\
\hline & 10 & $\mathrm{R}$ & 2 & 0 & 3 & 2 \\
\hline & 11 & $\mathrm{R}$ & 2 & 1 & 2 & 1 \\
\hline & 12 & $\mathrm{R}$ & 3 & 1 & 2 & 0 \\
\hline & Median & & 2 & 1 & 2 & 1.5 \\
\hline \multicolumn{7}{|l|}{ Glue control } \\
\hline & 4 & $\mathrm{~L}$ & 3 & 0 & 2 & 0 \\
\hline & 9 & $\mathrm{~L}$ & 2 & 1 & 2 & 0 \\
\hline & 10 & $\mathrm{~L}$ & 2 & 1 & 1 & 0 \\
\hline & 11 & $\mathrm{~L}$ & 2 & 1 & 2 & 1 \\
\hline & 12 & $\mathrm{~L}$ & 2 & 0 & 1 & 0 \\
\hline & 13 & $\mathrm{~L}$ & 2 & 1 & 2 & 1 \\
\hline & 14 & $\mathrm{~L}$ & 3 & 0 & 1 & 1 \\
\hline & 15 & $\mathrm{~L}$ & 2 & 0 & 2 & 0 \\
\hline & 16 & $\mathrm{R}$ & 3 & 1 & 1 & 0 \\
\hline & Median & & 2 & 1 & 2 & 0 \\
\hline \multicolumn{7}{|l|}{ Control } \\
\hline & 1 & $\mathrm{~L}$ & 0 & 0 & 0 & 0 \\
\hline & 2 & $\mathrm{~L}$ & 1 & 0 & 1 & 0 \\
\hline & 3 & $\mathrm{~L}$ & 1 & 0 & 0 & 0 \\
\hline & 5 & $\mathrm{~L}$ & 1 & 0 & 0 & 0 \\
\hline & 6 & $\mathrm{~L}$ & 1 & 0 & 1 & 0 \\
\hline & 7 & $\mathrm{~L}$ & 1 & 0 & 2 & 0 \\
\hline & 8 & $\mathrm{~L}$ & 1 & 0 & 0 & 0 \\
\hline & 16 & $\mathrm{~L}$ & 1 & 0 & 1 & 0 \\
\hline & 17 & $\mathrm{~L}$ & 2 & 0 & 2 & 0 \\
\hline & Median & & 1 & 0 & 1 & 0 \\
\hline
\end{tabular}

Grading system: $0=$ no inflammatory cells, $1=$ small number of cells, $2=$ moderate number of cells, $3=$ large number of cells.

\section{Materials and Methods}

The animal experiment was designed under the German Animal Protection Act and accepted by the commission for animal protection in Cologne, Germany. The registered file number is 50.203.2-BN 3,23/00.

The experimental design on the canine femoral artery described by Oiwa and colleagues ${ }^{5}$ was adapted for the carotid artery of the rabbit ${ }^{4}$ and formed the basis for this study.

Thirty-four carotid arteries of 17 female New Zealand White rabbits (Kaninchenzucht Lamers, Euskirchen, Germany), weighing 3.5 to $5 \mathrm{~kg}$ and aged 15 to 20 weeks, were used. Both common carotid arteries of the 17 rabbits were dissected. In 16 animals, the right side was centrally transected and glue was applied to create an anastomosis (group G). The contralateral (left) side was left unmanipulated in half of them, and thus served as part of the control group (group C). Glue was applied to the ventral surface of the left side in the other half of them (glue control = group GC).
In 1 rabbit, the left artery was unmanipulated (group C) and glue was applied to the ventral surface of the right artery (group GC). This resulted in 9 control arteries, 9 glue control arteries, and 16 glued anastomoses. In 3 of the glued anastomoses, the dissection process resulted in damage to the wall, which made suturing necessary. This resulted in exclusion of these 3 arteries from the study, leaving 13 glued vessels for angiographic evaluation. The complete destruction of 1 of the angiographically evaluated anastomoses by an abscess only allowed histologic assessment in 12 of 16 glued anastomoses (Table 1).

\section{Surgery}

All animals were anesthetized with a combination of ketamine hydrochloride (Ketavet, Pharmacia GmbH, Erlangen, Germany) and xylazine hydrochloride (Rompun, Bayer Vital GmbH, Leverkusen, Germany). The animals were prepared and positioned, 
and the common carotid artery was dissected as described earlier. ${ }^{4}$ In group $\mathrm{G}$ the dissected common carotid artery was crossclamped and transected, and a glued end-to-end anastomosis was performed with the aid of an inflated percutaneous transluminal coronary artery angioplasty balloon catheter (Cordis, Johnson \& Johnson, South Ascot, Great Britain) as described. ${ }^{4}$ The site of retrograde catheter introduction at the external carotid artery was sutured after removal of the catheter. The patency of all end-to-end anastomoses was assessed with an intraoperative perivascular flowprobe (HQ-Series Perivascular Flowprobes, Transonic Systems Inc, Ithaca, NY) before closure of the surgical site. In group GC the common carotid artery was freed from the surrounding tissue; no clamp was used, and the artery was not transected. The glue was applied to the ventral aspect of the artery over a length of $1.5 \mathrm{~cm}$ with a thickness of 2 to $3 \mathrm{~mm}$. In group $\mathrm{C}$ the common carotid artery was dissected in the same manner as in groups G and GC but not further manipulated. In all animals the surgical site was closed in accordance with the anatomy, and the rabbits were kept in cages for 60 days.

\section{Angiographic Analysis}

To identify stenoses, abscesses, or pseudoaneurysms associated with the anastomosis sites, digital subtraction angiography was performed on the anesthetized animals 60 days after the surgical intervention. A catheter was placed into the femoral artery and advanced into the common carotid artery. Contrast medium (Solutrast 300, Bracco-Byk-Gulden, Konstanz, Germany) was injected under radioscopic guidance (Multistar TOP, Siemens, Germany), and the results were documented in 2 planes.

Stenosis was scored as follows: grade 0 with a luminal narrowing of up to $25 \%$, grade 1 with a luminal narrowing of between $25 \%$ and $50 \%$, and grade 2 with a narrowing of more than $50 \%$.

While still anesthetized, the rabbits were euthanized with an injection of T61 (Hoechst Veterinaer Co, Frankfurt, Germany). The carotid arteries were removed, longitudinally opened, macroscopically assessed, and fixed in a $4 \%$ formaldehyde solution (Roti-Histofix, Carl Roth $\mathrm{GmbH}+\mathrm{Co}$, Karlsruhe, Germany).

\section{Macroscopic Assessment}

The surgery sites were macroscopically assessed for homogeneity and firmness of the glue, and capsule formation around the glue. Calcification, abscesses, thrombi, and stenoses were noted where they occurred.

\section{Microscopic Assessment}

For standard histologic assessment, localization of glue degradation, and identification of inflammatory cells, the slides were stained with hematoxylin-eosin. For the localization of the inflammatory cells, the immunohistological stain MAC 387 (NatuTec Systeme GmbH, Frankfurt, Germany) was used. This stain recognizes the intracytoplasmatic calprotectin antigen, which is expressed by granulocytes, monocytes, and macrophages and gives their cytoplasm a red color.

The general inflammatory reaction and the amount of individual cells (macrophages, granulocytes, and giant and foam cells) were evaluated with a grading system from 0 to 3 . This was done at 5 different sites within the largest accumulation of cells and
TABLE 2. Angiographic and macroscopic findings in 31 of 34 carotid arteries

\begin{tabular}{lccc}
\hline & $\mathbf{C}(\mathbf{N}=\mathbf{9})$ & $\mathbf{G C}(\mathbf{N}=\mathbf{9})$ & $\mathbf{G}(\mathbf{N}=\mathbf{1 3})$ \\
\hline Aneurysm & 0 & 0 & 4 \\
Stenosis & 0 & 9 & 13 \\
Thrombus & 0 & 0 & 10 \\
Abscess & 0 & 0 & 4 \\
Capsule & 0 & 9 & 13 \\
Calcification & 0 & 9 & 13
\end{tabular}

Groups: $\mathrm{C}=$ control group; $\mathrm{GC}=$ glue control; $\mathrm{G}=$ glued anastomoses.

therefore the strongest inflammatory reaction at a magnification of $\times 1000$. Subsequently, the median for each cell type was identified.

- Grade 0: no inflammatory cells

- Grade 1: small number (1-3 cells)

- Grade 2: moderate number (4-10 cells)

- Grade 3: large number ( $>10$ cells)

The Elastica van Giessen stain was used to show the presence and distribution of elastic fibers in the capsule and vessel. To determine the extent of collagen fiber deposits, the Sirius red stain was used. A modified van Kossa stain differentiated between atheromatous cholesterol plaques and calcium-phosphor deposits.

\section{Results}

Intraoperative blood flow measurements of all arteries immediately before neck closure confirmed the patency and pulsatility.

\section{Aneurysm, Stenosis, and Thrombus}

The control group (group C) showed no abnormalities. All 9 arteries in the glue control group (group GC) showed a mild degree of stenosis (grade 1), and all 13 arteries in the glued anastomosis group showed some degree of stenosis. A grade 2 stenosis with complete thrombotic occlusion was present in 10 of 13 (77\%) of the anastomoses; in 1 artery this was due to the formation of a large abscess that had been described as a firm swelling 3 days before the trial period of 60 days ended. The abscess had completely destroyed the anastomosis and the adjacent artery and was excluded from the microscopic assessment. An associated pseudoaneurysm was observed in 3 of 10 arteries, a dissociation of glue and the vessel stump was observed in 4 arteries, and small abscesses were observed in 2 of 10 arteries. In another artery, the reason for the occlusion remained unclear. A grade 1 stenosis was present in the remaining 3 of 13 arteries, 1 of which was associated with a pseudoaneurysm (Table 2; Figure 1).

\section{Glue Consistency}

The consistency of the glue was porous and fragile, with fragments separated from the otherwise homogeneous block of adhesive. Microscopically the fragments were surrounded by inflammatory cells. All 21 (9 in group GC and 


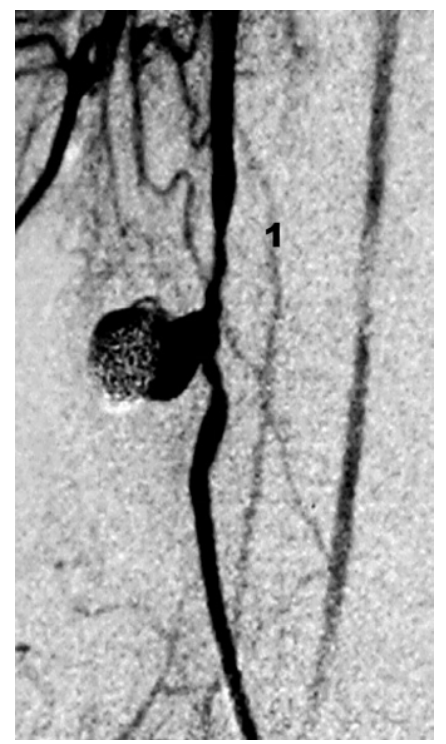

Figure 1. Digital subtraction angiogram of the right common carotid artery: pseudoaneurysm with stenosis grade 3 in group $\mathbf{G}$. $1=$ grade 3 stenosis.

12 in group G) vessels exposed to the adhesive showed microscopic disintegration of the glue. Active phagocytosis was present everywhere on the glue to artery interfaces in 9 of 9 arteries in the glue control group and in 9 of 12 of the glued anastomoses. In the remaining 3 of 12 arteries, the phagocytosis was only present between the capsule and the glue.

\section{Capsule}

No capsule was present in group C (Table 2). All 21 arteries exposed to glue (groups G and GC) developed a capsule with a thickness of 0.5 to $1.5 \mathrm{~mm}$, precisely encircling the outer surface of the glue (Figure 2). The hematoxylin-eosin and Elastica van Giessen stains revealed a massive number

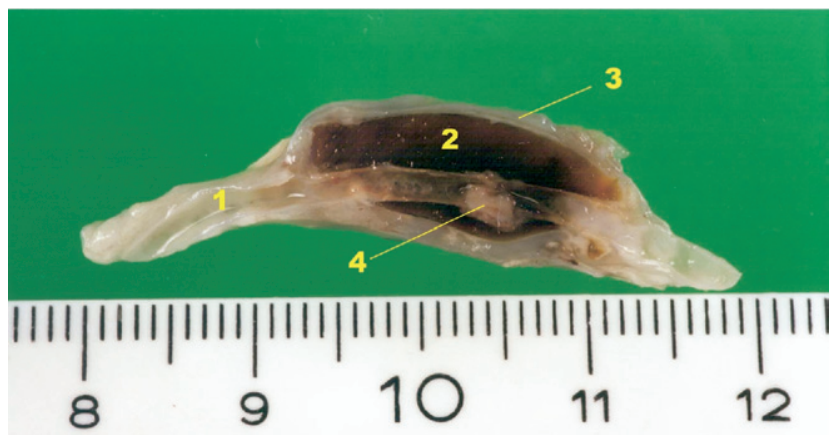

Figure 2. Macroscopic capsule formation of a common carotid artery in group $\mathbf{G}$, longitudinal section. 1 = arteria carotis communis, 2 = glue, $3=$ capsule, $4=$ mineralized plaque.

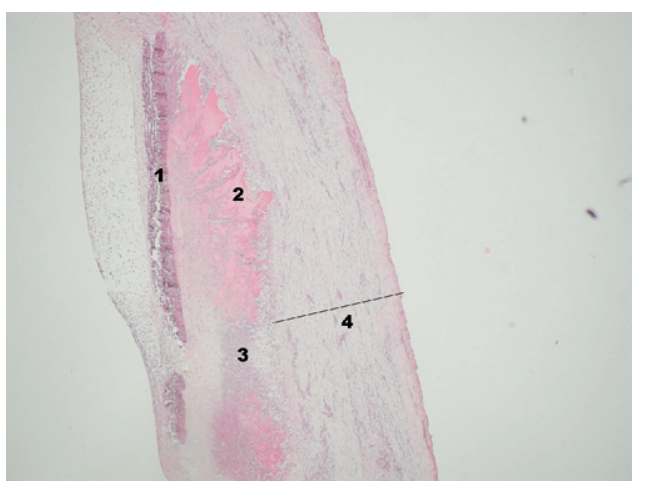

Figure 3. Capsule, glue, and arterial wall in group $\mathbf{G}$; hematoxylin-eosin stain, magnification $\times \mathbf{2 0 0} .1=$ calcification, $2=$ degradation of glue, 3 = degradation of glue with collagen synthesis, $4=$ capsule.

of fibroblasts that gave the capsules a scar-like character (Figure 3). The Sirius red stain confirmed collagen deposition (Figure 4). Regions with degradation of the glue by macrophages and granulocytes showed a higher reactive fibroblast activation, and the defects were partially filled with connective tissue. No animal in group $\mathrm{C}$ showed collagen deposits.

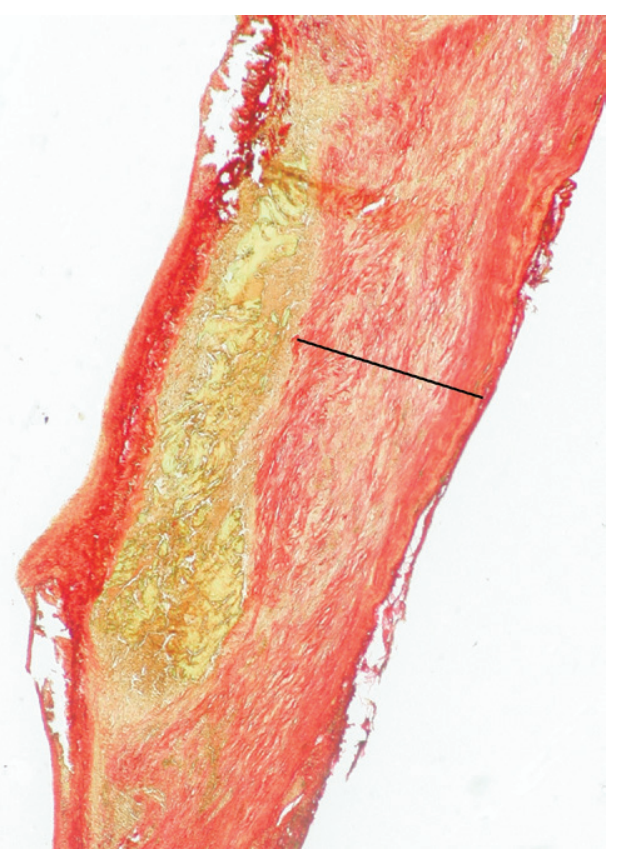

Figure 4. Same artery as in Figure $3 A$, stained with Sirius red. Magnification $\times 40$. Collagen (red); thickness of the capsule (black line). 


\begin{abstract}
Abscess
No abscesses were present in groups GC and C (Table 2). In addition to the single large abscess detected with angiography in group $\mathrm{G}$, dissection revealed 2 further arteries with a small abscess located between the capsule and the glue. In these 2 cases the anastomoses were still evident, but their lumen was completely occluded.
\end{abstract}

\section{Calcification}

All 21 carotids exposed to the glue (groups G and GC) showed a variable degree of calcification in the wall under the adhesive (Table 2; Figures 2 and 3, A). In the group with only glue (group GC), the calcium deposits were located between the adventitia and the media, whereas no predilection site could be identified in the group of glued anastomoses. No calcium deposits were detectable in group C.

\section{Inflammation}

The control group (group C) showed sporadic macrophages and a physiologic number of foam cells (Table 1). All 21 arteries of the glue-exposed groups ( $\mathrm{G}$ and $\mathrm{GC}$ ) showed a moderate-to-severe inflammatory reaction (grades 2 and 3 ). The presence, differentiation, and distribution of granulocytes, macrophages, and giant and foam cells gave the inflammation a prevailing granulomatous character. The circumferential layering of different stages of inflammation and inflammatory cells was limited to the glue. On viewing the layers from the glue outward, a chronologic sequence of glue degradation became evident. Close to the glue, granulocytes and macrophages with phagocytotic activity resulted in gaps and lacunae within the glue. This layer was followed by cells with an extremely large cytoplasmatic body, representing the evolution from macrophages to foam cells. A third layer consisted of giant cells. The presence of tissue macrophages, giant and foam cells, and granulocytes, as well as their detritus in the form of tiny red granules in the surrounding tissue, was confirmed in the MAC 387 stain (Figure 5).

\section{Discussion}

The promising early postoperative results of BioGlue in the literature $^{1,2}$ were not confirmed in this medium-term study. Gundry and colleagues ${ }^{1}$ described an incomplete reabsorption of the glue with capsule formation in 1 of 3 goats, resulting in adhesions between the pericardium and the anastomosed bypass. This is in accordance with the findings of our short-term study, ${ }^{4}$ in which all arteries exposed to glue (groups G and GC) showed a local increase of fibroblasts and disorganized eosinophilic fibers that represent early scar formation. This was limited to the application site of the glue.

The large amount of connective tissue formation and the presence of giant cells in the present study indicate a

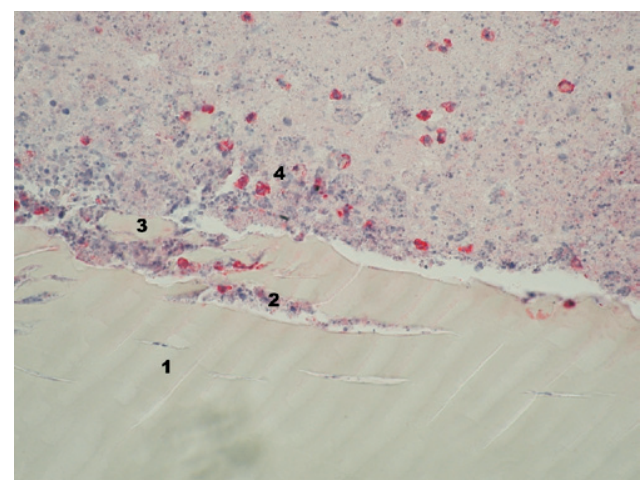

Figure 5. Red stained macrophages and degradation of glue in group G; MAC 387 stain, magnification $\times 1000.1=$ glue, $2=$ ingrown island of tissue with inflammatory cells, $3=$ fragmented glue, $4=$ MAC red stained macrophages and cell debris.

chronic inflammatory reaction similar to the foreign body reaction described by van Belleghem and colleagues. ${ }^{6}$ The chronic inflammatory process is most likely caused by the adhesive itself because the contralateral control arteries in group $\mathrm{C}$ did not develop a capsule or show a pathologic increase in the number of inflammatory cells. The marked inflammatory reaction observed in the present study was also described by Herget and colleagues ${ }^{7}$ in their article on the use of BioGlue in caprine and rabbit anastomoses of trachea and bronchi, in Wipperman and colleagues' study ${ }^{3}$ on porcine coronary artery anastomoses, and in our shortterm study, ${ }^{4}$ in which intense inflammatory reaction and glue degradation were present in the region of the gap. The glue breakdown and replacement by connective tissue was also described by van Belleghem and colleagues ${ }^{6}$ in canine external iliac arteries in which the foam and giant cells did not appear until day 90 . The presence of calcification associated with the glue has not been described and supports the assumption from our short-term study ${ }^{4}$ that nuclear loss and cell degeneration of the arterial wall may result in calcification in the long term. It is important to note that although the calcification in our study did not always affect the same part of the capsule or vessel wall, it was always limited to the application site of the glue. Glutaraldehyde has been classified by the European Union as a toxic substance [EU TN, UN 6], and Fürst and Banerjee ${ }^{8}$ described its cytotoxic effects on various tissues in vitro and in vivo. The formation of a pseudoaneurysm in association with thrombi and stenoses in the group with glued anastomoses could be due to the use of a balloon catheter and the subsequent irritation of the arterial endothelium. Picon and colleauges ${ }^{9}$ induced thrombi with the balloon technique in the rabbit aorta by destroying the endothelial layer. In our study, however, the endothelial surface was histologically intact. The present study suggests that the thrombus and pseudoaneurysm for- 
mations may have been encouraged by insufficient adaptation of the anastomosis ends because they developed only in the glued anastomosis group. Abscesses and pseudoaneurysm formation may be the result of insufficient replacement of degraded glue with solid scar tissue and consecutive localized bleeding from the anastomosis sites.

\section{Conclusions}

The application of BioGlue results in a marked invasion of inflammatory cells into the arterial wall after 60 days. Although the degraded glue is replaced with connective tissue, the associated inflammation and calcification of the arterial wall and capsule, as well as the formation of pseudoaneurysms at the glue application site, raise safety issues regarding the use of BioGlue during coronary artery bypass surgery. Our findings suggest that caution may be indicated with respect to the use of BioGlue in large vessel vascular surgery.

\section{References}

1. Gundry SR, Black K, Izutani H. Sutureless coronary artery bypass with biologic glued anastomoses: preliminary in vivo and in vitro results. J Thorac Cardiovasc Surg. 2000;120:473-7.
2. van Nooten G, van Belleghem Y, Foubert L, Francois K, Caes F, van Overbeke $\mathrm{H}$, et al. An experimental model of coronary anastomosis without suturing. Cardiovasc Surg. 2003;11:80-4

3. Wippermann J, Konstas C, Breuer M, Kosmehl H, Wahlers T, Albes JA. Long term effects in distal coronary anastomoses using different adhesives in a porcine off-pump model. J Thorac Cardiovasc Surg. 2006; 132:325-31.

4. Schiller W, Rudorf H, Kiderlen MJ, Welzel CB, Schmitz C, Probst C, et al. Short-term tissue response of lapine carotid artery microanastomoses to BioGlue. Thorac Cardiovasc Surg. 2007;55:298-303.

5. Oiwa H, Takamoto S, Murakami A, Tanaka O, Furuse A. Experimental study of small arterial anastomosis with gelatin-resorcin-formaldehyde glue and collagen sheet. Artif Organs. 2001;25:281-91.

6. van Belleghem, Forsyth RG, Narine K, Moerman A, Taeymans Y, van Nooten GJ. Bovine glue (BioGlue) is catabolized by enzymatic reaction in the vascular dog model. Ann Thorac Surg. 2004;77:2177-81.

7. Herget GW, Kassa M, Riede UN, Lu Y, Brethner L, Hasse J. Experimental use of an albumin-glutaraldehyde tissue adhesive for sealing pulmonary parenchyma and bronchial anastomoses. Eur J Cardiothorac Surg. 2001;19:4-9.

8. Fürst W, Banerjee A. Release of glutaraldehyde from an albuminglutaraldehyde tissue adhesive causes significant in vitro and in vivo toxicity. Ann Thorac Surg. 2005;79:1522-8.

9. Picon PD, Goncalves SC, Wainstein MV, Costa AF, Mengarda CV, Machado RP, et al. Atherosclerosis and acute arterial thrombosis in rabbits: a model using balloon desendothelization without dietary intervention. Braz J Med Biol Res. 1997;30:415-7. 